\title{
Antwort auf den offenen Brief der FMH
}

In der SÄZ Nr. 45/2012 reagierte die FMH mit einem offenen Brief auf die Behauptung von santésuisse, dass selbstdispensierende Ärztinnen und Ärzte sowohl über den Einzelleistungstarif TARMED als auch über die Marge Vergütungen für die Medikamente erhalten. * Nachfolgend nun als Faksimile die Antwort von santésuisse.

Die Redaktion

santésuisse

Römerstrasse 20

Postfach 1561

CH-4502 Solothurn

Tel. +41326254141

Fax +41326254151

mail@santesuisse.ch

www.santesuisse.ch

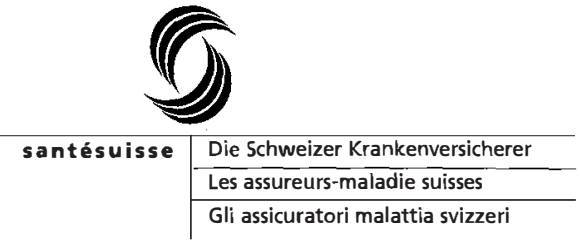

Dr. med. Jacques de Haller

Präsident FMH

Postfach 300

Elfenstrasse 18

3000 Bern 15

Solothurn, 6. November 2012

\section{Offener Brief der Ärzteschaft an Christoffel Brändli}

Sehr geehrter Herr Dr. de Haller

Wir bedauern, dass die von santésuisse in ihrer Medienmitteilung zum Medikamenten-

Margenvergleich verwendete Formulierung der "doppelten Vergütung" offenbar missverständlich war.

Es war nie unsere Absicht, nicht statthafte zweifache Verrechnungen für gleiche Leistungen zu insinuieren. Wir können nachvollziehen, dass sich die Ärzteschaft durch die missverständliche Formulierung in ein schlechtes Licht gerückt sehen konnte. Wir möchten uns bei allen Ärzten, welche sich dadurch verletzt fühlen, entschuldigen.

Das Anliegen von santésuisse war es vielmehr, die Höhe der Medikamentenmargen in allen drei Absatzkanälen in der Schweiz zu thematisieren und grundsätzliche Vorschläge für die Weiterentwicklung der Abgeltung anzuregen. Selbstverständlich müssen Vertriebsmargen wirtschaftlich begründbar sein und muss innen ein Nutzen bei den Versicherten gegenüberstehen.

Den Löhnen der Grundversorger stehen oft deutlich höhere Einkommen von Spezialärzten gegenüber. Unserer Auffassung nach sollten Ärzte - insbesondere auch die Grundversorger - für die eigentlichen ärztlichen Leistungen angemessen entschädigt werden und nicht substantiell auf Nebenleistungen wie Medikamentenabgabe oder Laboranalysen angewiesen sein. In diesem Sinne könnte die Tarifierung überdacht und gegebenenfalls angepasst werden.

Zugunsten weiterer Verbesserungen in der Gestaltung der Entschädigung für die Ärzteschaft und unter Wahrung der Kostenkontrolle, sind wir bestrebt, mit der FMH weiterhin konstruktiv und datenbasiert zusammenzuarbeiten und zu verhandeln.

Freundliche Grüsse

de Haller J, Gähler E. Falsche und ungerechtfertigte Unterstellungen gefährden zukünftige Verhandlungen. Schweiz Ärztezeitung. 2012;93(45):1640
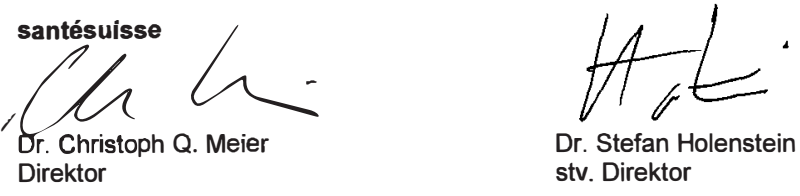

Dr. Stefan Holenstein stv. Direktor 